\title{
Surface Electrochemistry of CO on Pt(111): Anion Effects
}

\author{
N. M. Markovic ${ }^{1}$, C. A. $\operatorname{Lucas}^{2}$, A. $\operatorname{Rodes}^{3}$, V. Stamenkovic ${ }^{1}$, P. N. Ross ${ }^{1}$ \\ 1) Materials Sciences Division Lawrence Berkeley National Laboratory University of \\ California Berkeley, CA 94720 \\ 2) Oliver Lodge Laboratory, Department of Physics, University of Liverpool, Liverpool \\ 3) Departemento de Quimica Fisica, Unversidad de Alcante, E-03083 Alicante, Spain
}

\begin{abstract}
In-situ studies of $\mathrm{CO}$ adsorption by surface x-ray scattering (SXS) and Fourier transform infrared (FTIR) spectroscopy techniques are used to create the link between the macroscopic kinetic rates of $\mathrm{CO}$ oxidation and the microscopic level of understanding the structure/site occupancy of $\mathrm{CO}$ on $\mathrm{Pt}(111)$. A remarkable difference in activity was observed between alkaline and acid solutions. In alkaline solution the oxidation of $\mathrm{CO}$ proceeds at low overpotential $(<0.2 \mathrm{~V})$ by the surface reaction between the adsorbed $\mathrm{CO}$ and $\mathrm{OH}$, the latter forming selectively in the hydrogen underpotential potential region at defect sites. In acid solution these sites are blocked by specific adsorption of anions, and consequently in a solution containing $\mathrm{Br}^{-}$the ignition potential is shifted positively by $0.6 \mathrm{~V}$. Anions of supporting electrolytes also have dramatic effects on both the potential range of stability and the domain size of the $\mathrm{p}(2 \mathrm{x} 2)-3 \mathrm{CO}$ structure which is formed at $0.05 \mathrm{~V}$. The stability/domain size of this structure increases from $\mathrm{KOH}$ (ca. $30 \AA$ between $0.05<\mathrm{E}<0.3 \mathrm{~V})$, to $\mathrm{HClO}_{4}(c a .140 \AA$ between $0.05<\mathrm{E}<0.6 \mathrm{~V})$ to $\mathrm{HClO}_{4}+\mathrm{Br}^{-}(c a$ $350 \AA$ between $0.05<\mathrm{E}<0.8 \mathrm{~V})$. The larger the ordered domains of the $\mathrm{p}(2 \times 2)-\mathrm{CO}_{\mathrm{ad}}$ structure are, the less active the surface is towards $\mathrm{CO}$ oxidation.
\end{abstract}

\footnotetext{
* Corresponding author: nmmarkovic@lbl.gov
} 


\section{INTRODUCTION}

Carbon monoxide is the simplest $\mathrm{C}_{1}$ molecule that can be electrochemically oxidized in a low temperature fuel cell at a reasonable (although not necessarily practical) potential. It thus serves as an important model "fuel" for fundamental studies of $\mathrm{C}_{1}$ electrocatalysis. Just as in heterogeneous catalysis, the ultimate challenge in electrocatalysis science is to relate the microscopic details of adsorbed states of intermediates to the macroscopic measurement of kinetic rates and thermodynamic state functions. Unfortunately, in the case of surface chemistry of $\mathrm{CO}$ on $\operatorname{Pt}(h k l)$ surfaces, this approach has an intrinsic difficulty. Given that $\mathrm{CO}$ adsorption on $\operatorname{Pt}(h k l)$ at near ambient temperature is an irreversible process, and due to the narrow temperature range available in aqueous solutions, the heat of adsorption of $\mathrm{CO}$ cannot be determined at Pt electrodes. One can use, however, the values of thermodynamic functions which are obtained from UHV measurements and test them in the electrochemical system for consistency. Two general features in the energetics of the $\mathrm{CO}_{\mathrm{ad}} / \mathrm{Pt}$ system clearly emerge from the UHV studies: that the heat of adsorption of $\mathrm{CO}$ on $\mathrm{Pt}(h k l)$ is strongly coverage dependent ${ }^{1}$ and that the heats of $\mathrm{CO}$ adsorption are relatively insensitive to the surface structure of the substrate ${ }^{2 ; 3}$. From these general observations, it was suggested that at the $\operatorname{Pt}(111)$ /solution interface the heats of adsorption at saturation coverage of $\mathrm{CO}_{\mathrm{ad}}$ are close to $\approx 1 / 3$ of the initial value ${ }^{4}$, e.g. a heat of adsorption of $\mathrm{CO}$ at $\operatorname{Pt}(111)$ aqueous electrolytes may vary from $\approx 150 \pm 15 \mathrm{~kJ} / \mathrm{mol}$ at low coverages to $\approx 65 \pm 15 \mathrm{~kJ} / \mathrm{mol}$ at saturation. Closely following UHV terminology, we proposed that energetically two forms of $\mathrm{CO}_{\mathrm{ad}}$ species can be distinguished on $\mathrm{Pt}(111)$ in an electrochemical environment": (i) $\mathrm{CO}_{\mathrm{ad}}$ with a low heat of adsorption is characterized as the "weakly adsorbed" state, $\mathrm{CO}_{\mathrm{ad}, \mathrm{w}}$, and (ii) $\mathrm{CO}_{\mathrm{ad}}$ with a relatively high enthalpy of adsorption is characterized as the "strongly adsorbed" state, $\mathrm{CO}_{\mathrm{ad}, \mathrm{s}}$. These concepts for $\mathrm{CO}_{\mathrm{ad}}$ energetics, and the transition from the $\mathrm{CO}_{\mathrm{ad}, \mathrm{w}}$ layer into the $\mathrm{CO}_{\mathrm{ad}, \mathrm{s}}$ state, are the keys to understanding 
the relation between reactivity and interfacial structures of $\mathrm{CO}_{\mathrm{ad}}$ on the $\operatorname{Pt}(h k l)$. Independent, non-electrochemical insight into the $\mathrm{Pt}(111)-\mathrm{CO}$ system was obtained by combination of in-situ structure-sensitive probes, such as scanning tunneling microscopy (STM) ${ }^{6 ; 7}$ and surface $\mathrm{x}$-ray scattering (SXS), ${ }^{8}$ with in-situ adsorption-site-sensitive probes, such as Fourier transform infrared (FTIR) spectroscopy ${ }^{6 ; 7 ; 9}$ and sum frequency generation (SFG) ${ }^{9}$. These studies demonstrated that, although the nature and adsorption site occupancy of $\mathrm{CO}_{\mathrm{ad}}$ are strongly dependent of applied potential, the mechanism for $\mathrm{CO}_{\mathrm{ad}}$ oxidation on $\mathrm{Pt}(111)$ is independent of electrode potential; e.g., $\mathrm{CO}_{\mathrm{ad}}$ reacts with $\mathrm{OH}_{\mathrm{ad}}$, species through either non-competitive or competitive Langmuir-Hinshelwood (LH) type reaction ${ }^{5}$ :

$$
\mathrm{CO}_{a d}+\mathrm{OH}_{a d}=\mathrm{CO}_{2}+\mathrm{H}^{+}+e^{-}
$$

Furthermore, it was suggested that the kinetics of reaction (1) does not depend only on the surface concentration of $\mathrm{CO}_{\mathrm{ad}}$ and $\mathrm{OH}_{\mathrm{ad}}$ species, but is strongly affected by a delicate balance between the coverage of $\mathrm{CO}_{\mathrm{ad}}, \mathrm{OH}_{\mathrm{ad}}$ and anions from supporting electrolytes ${ }^{5 ; 10}$.

In this paper we describe the role of anions in controlling both the kinetics of $\mathrm{CO}_{\mathrm{b}}$ electrooxidation on $\operatorname{Pt}(111)$ in aqueous electrolytes and the potential range of stability of $\mathrm{p}(2 \times 2)-3 \mathrm{CO}$ structure, which is formed on the $\mathrm{Pt}(111)$ surface at low overpotentials. Polarization curves for $\mathrm{CO}_{\mathrm{b}}$ oxidation on $\mathrm{Pt}(111)$ are compared in alkaline solution, perchloric acid solution, and perchloric acid solution containing $\mathrm{Br}^{-}$. The kinetics of $\mathrm{CO}$ oxidation were measured by utilizing the rotating disk electrode (RDE) method. Direct information regarding the anion effect on the $\mathrm{CO}_{\mathrm{ad}}$ structure and site occupancy was obtained from SXS and FTIR measurements. In combination, these three techniques allow to illuminate the development of a new insight into relation between the microscopic details of the $\mathrm{Pt}(111)-\mathrm{CO}_{\mathrm{ad}}$ interface and the kinetics of $\mathrm{CO}$ electrooxidation.

\section{EXPERIMENTAL}




\subsection{Electrochemical measurements}

Most of the experimental details were described previously ${ }^{10}$. Following the flame annealing-hydrogen (or argon) cooling method, the $\mathrm{Pt}(111)$ electrode was transferred into the disk configuration of the RDE. The cleanliness of the transfer and the electrolyte, even under sustained rotation at high rotation rates, were demonstrated in our previous work ${ }^{11}$. For the electrooxidation of dissolved pure $\mathrm{CO}$ gas (denoted hereafter as $\mathrm{CO}_{\mathrm{b}}$ ), the electrolyte was firstly equilibrated for 5 minutes with the respective gas while the electrode potential was held at $0.05 \mathrm{~V}$, and subsequently the positive was scanned (20 $\mathrm{mV} / \mathrm{s}$ ). The kinetics of $\mathrm{CO}_{\mathrm{b}}$ oxidation was in three different electrolytes: $0.1 \mathrm{M} \mathrm{NaOH}$, $0.1 \mathrm{M} \mathrm{HClO}_{4}$, and $0.1 \mathrm{M} \mathrm{HClO}_{4},+10^{-2} \mathrm{M} \mathrm{Br}^{-}$. The reference electrode was a saturated calomel electrode (SCE) at $298 \mathrm{~K}$ separated by an electrolyte bridge. However, all potentials are referred to the reversible hydrogen electrode.

\subsection{FTIR measurement}

FTIR experiments were performed with a Nicolet Magna 850 spectrometer equipped with a MCT detector. The Pt(111) single crystal electrode employed (ca. 4.5 $\mathrm{mm}$ in diameter) was prepared by using the method developed by Clavilier ${ }^{12}$. The flameannealed electrode was rinsed with water and transferred to a spectroelectrochemical cell provided with a prismatic $\mathrm{CaF}_{2}$ window bevelled at $60^{\circ}$. Once a cyclic voltammogram was recorder in order to check the cleanliness of the electrode surface, the solution was saturated with $\mathrm{CO}$ while holding the electrode potential at $0.10 \mathrm{~V}$. Spectra were then collected with p-polarized light and a resolution of $8 \mathrm{~cm}^{-1}$ while the electrode potential was swept at $1 \mathrm{mV} \mathrm{s}^{-1}$ up to $1.0 \mathrm{~V}\left(0.1 \mathrm{M} \mathrm{HClO}_{4}\right.$ and $0.1 \mathrm{M} \mathrm{NaOH}$ solutions $)$ or up to $1.2 \mathrm{~V}\left(0.01 \mathrm{M} \mathrm{KBr}+0.1 \mathrm{M} \mathrm{HClO}_{4}\right)$. Typically, $10 \mathrm{~s}$ were needed to collect 104 interferograms which were co-added to obtain each single beam spectrum corresponding to a potential window of $10 \mathrm{mV}$. Absorbance spectra were calculated as the ratio $-\log$ $\left(\mathrm{R} / \mathrm{R}_{0}\right)$ where $\mathrm{R}$ and $\mathrm{R}_{0}$ are the reflectance values corresponding to the sample and 
reference single beam spectra, respectively. Either the spectrum collected at the upper potential limit, i.e. after the oxidative stripping of adsorbed $\mathrm{CO}$, or that obtained at $0.10 \mathrm{~V}$ were used as the reference spectrum.

\subsection{X-ray scattering measurements}

The $\operatorname{Pt}(111)$ crystal (miscut $<0.2^{\circ}$ ) was prepared by annealing in a hydrogen flame and then transferred under electrolyte to the $\mathrm{x}$-ray electrochemical cell ${ }^{8}$. The cell was mounted at the center of a four-circle Huber goniometer on beamline 7-2 at the Stanford Synchrotron Radiation Laboratory (SSRL). SXS measurements were performed using a focused monochromatic x-ray beam of energy $10 \mathrm{keV}$, defined by slits to be a $1 \mathrm{~mm}$ x 1 mm spot at the sample. Diffracted x-rays were measured by a Ge solid state detector after passing through a Soller slit which defined an in-plane resolution of $\sim 0.005 \AA^{-1}$. The crystal was indexed to the conventional hexagonal until cell for the (111) surface. The adsorption of $\mathrm{CO}$ was studied by purging the outer shell of the $\mathrm{x}$-ray cell with $\mathrm{CO}$ (99.999\% purity) which was then able to diffuse through the polypropylene film trapping the electrolyte and saturate the solution.

\section{RESULTS AND DISCUSSION}

Recently, we proposed that two potential regions can be distinguished in the current vs potential relationship during $\mathrm{CO}_{\mathrm{b}}$ oxidation on $\operatorname{Pt}(111)$ : a potential region of the electrooxidation via the weakly adsorbed state of CO (the so called pre-ignition or preoxidation potential region ${ }^{13 ; 14}$ ) and the potential region of the oxidation via the strongly adsorbed state of $\mathrm{CO}_{\mathrm{ad}}$ (the so called ignition potential region). The ignition potential is the electrochemical analog of ignition temperature for the gas phase oxidation of CO. It is the potential at which the rate becomes entirely mass transfer limited (rate of $\mathrm{CO}_{\mathrm{b}}$ diffusion to the surface). Recall that although the nature of $\mathrm{CO}_{\mathrm{ad}}$ changes with electrode potential, the mechanism for $\mathrm{CO}_{\mathrm{ad}}$ oxidation on $\mathrm{Pt}(h k l)$ follows the $\mathrm{L}-\mathrm{H}$ reaction 
mechanism in the entire potential range ${ }^{5}$. Other research groups have proposed different models for CO oxidation. In particular, Bergelin et al., ${ }^{15 ; 16}$ suggested that in the preignition potential region $\mathrm{CO}$ oxidation cannot proceed through the $\mathrm{L}-\mathrm{H}$ mechanism, but rather through an Eley-Rideal (E-R) mechanism, i.e. reaction between $\mathrm{CO}_{\mathrm{ad}}$ and "activated" water molecules in the electrical double-layer. Rather than debate the interpretations here, the interested reader is referred to the original references for details. In this paper, $\mathrm{CO}$ oxidation on $\mathrm{Pt}(111)$ will be considered to proceed through the $\mathrm{L}-\mathrm{H}$ mechanism, in which the kinetics is strongly dependent on the delicate balance between the surface coverage of $\mathrm{CO}_{\mathrm{ad}}, \mathrm{OH}_{\mathrm{ad}}$ and anions from supporting electrolytes.

\subsection{Anion effects on the kinetics of $\mathrm{CO}_{\mathrm{b}}$ oxidation}

The role of anions in the supporting electrolyte on the kinetics of $\mathrm{CO}_{\mathrm{b}}$ electrooxidation can be seen by comparing the polarization curves for $\mathrm{CO}_{\mathrm{b}}$ oxidation on $\operatorname{Pt}(111)$ in different electrolytes, e.g., alkaline solution, perchloric acid solution, and perchloric acid solution containing $\mathrm{Br}^{-}$. Figure 1 shows that the activity of $\operatorname{Pt}(111)$ increases in the sequence: $\mathrm{Br}^{-}<<\mathrm{HClO}_{4}<<\mathrm{NaOH}$. In the latter case, the onset of the pre-ignition region is in what is generally considered to be the $\mathrm{H}_{\text {upd }}$ potential region (!). If the L-H mechanism is operative, the catalytic activity in the $\mathrm{H}_{\text {upd }}$ potential region implies that in alkaline solution $\mathrm{OH}_{\mathrm{ad}}$ is adsorbed even at potentials below ca. $0.2 \mathrm{~V}$ (RHE). This would translate into an increase in the $\mathrm{Pt}-\mathrm{OH}_{\mathrm{ad}}$ bond energy by $c a .70-80 \mathrm{~kJ} / \mathrm{mol}$, from $136 \mathrm{~kJ} / \mathrm{mol}$ in acidic solution to $\mathrm{ca}$. 206-216 kJ/mol. We had proposed that adsorption of $\mathrm{OH}_{\mathrm{ad}}$ with this higher bond energy occurs at the defect/step sites on the $\mathrm{Pt}(111)$ surface ${ }^{10}$. The low defect density on this surface explains the relatively low rate of reaction achieved in this potential region. On the $\operatorname{Pt}(100)$ surface, where the defect density is high due to the lifting of the reconstruction, the activity in the same potential region is much higher than on $\operatorname{Pt}(111){ }^{17}$. The explanation, therefore, for the remarkable effect of $\mathrm{pH}$ on the rate of $\mathrm{CO}_{\mathrm{b}}$ oxidation on $\mathrm{Pt}(\mathrm{hkl})$ is the " $\mathrm{pH}$ dependent" adsorption of $\mathrm{OH}_{\mathrm{ad}}$ at 
defect/step sites. In acid solution at low overpotentials $\mathrm{OH}_{\mathrm{ad}}$ is most likely excluded from active sites, e.g., the dipole moment at defect/step sites is intrinsically attractive to anions 10. The fact that in solution containing bromide the ignition potential is shifted ca. $0.6 \mathrm{~V}$ positively from one observed in alkaline solution implies that $\mathrm{Br}^{-}$can indeed effectively suppress the adsorption of $\mathrm{OH}_{\mathrm{ad}}$. As a consequence, in solution containing bromide a diffusion limiting current is not observed for $\mathrm{CO}_{\mathrm{b}}$ oxidation even above $1.1 \mathrm{~V}$. In fact, a close inspection of Figure 1 clearly reveals that in the presence of $\mathrm{Br}^{-}$a bulk oxidation of $\mathrm{CO}$ is more similar to the stripping voltammetry of $\mathrm{CO}_{\mathrm{ad}}$ than to characteristic polarization curves for $\mathrm{CO}_{\mathrm{b}}$ oxidation in $0.1 \mathrm{M} \mathrm{HClO}_{4}$ and $0.1 \mathrm{M} \mathrm{NaOH}$. The supposition that the active centers are the defect/steps sites is fully consistent with the recent results for the electrooxidation of $\mathrm{CO}$ on stepped $\mathrm{Pt}[\mathrm{n}(111) \mathrm{x}(111)]$ electrodes. Lebedeva et al.,

${ }^{18}$ showed that the onset potential for oxidation of dissolved CO increases in the sequence $\operatorname{Pt}(553)<\operatorname{Pt}(554)<\operatorname{Pt}(111)$.

\subsection{Effects of anions on the surface structure of $\mathrm{CO}_{\mathrm{ad}}$}

Aside from the pioneering STM studies by Villegas and Weaver ${ }^{6 ; 7}$, and later studies by our group using SXS ${ }^{8 ; 9 ; 19}$, there is very little information about the interplay between the substrate structure and the bonding geometry of the $\mathrm{CO}_{\mathrm{ad}}$ molecules on $\mathrm{Pt}(111)$. In the SXS experiments ${ }^{8}$, direct information regarding the $\mathrm{CO}_{\mathrm{ad}}$ structure on $\mathrm{Pt}(111)$ in perchloric acid solution was obtained since the $\mathrm{CO}_{\mathrm{ad}}$ formed an ordered adlayer with $p(2 \times 2)$ symmetry and the diffraction signal from this structure could be followed as the electrode potential was changed. Valuable complementary information can be obtained from vibrational spectroscopies, such as FTIR and SFG. In this section we describe SXS and FTIR combined studies in application to the atomic-structure of $\mathrm{CO}_{\mathrm{ad}}$ on $\mathrm{Pt}(111)$ in alkaline solution and in acid solution containing $\mathrm{Br}^{-}$. For completeness, the original results obtained for the $\mathrm{Pt}(111)-\mathrm{CO}$ system in perchloric acid are also shown. 
In perchloric acid solution, Figure 2, while holding the potential at $0.05 \mathrm{~V}$ and with a continuous supply of $\mathrm{CO}$ to the $\mathrm{x}$-ray cell, a diffraction pattern consistent with a $\mathrm{p}(2 \times 2)$ symmetry was observed ${ }^{8}$, which is in a good agreement with previous STM results ${ }^{6}$. Figure $2 \mathrm{a}$ shows that the potential range of stability of the $\mathrm{p}(2 \times 2)-3 \mathrm{CO}$ phase, with a $\mathrm{CO}$ coverage of $0.75 \mathrm{ML}$, is strongly affected by the oxidation of a small fraction (15\%) of the saturation coverage. With a constant overpressure of $\mathrm{CO}$ in the $\mathrm{x}$-ray cell, the SXS experiments revealed a reversible order-disorder transition of the $\mathrm{p}(2 \times 2)-3 \mathrm{CO}$ structure, with the $\mathrm{p}(2 \times 2)-3 \mathrm{CO}$ structure re-forming as the potential was slowly $(1 \mathrm{mV} / \mathrm{s})$ swept below $0.2 \mathrm{~V}$, Figure 2a. Besides the $\mathrm{p}(2 \times 2)$ structure, markedly different $\mathrm{CO}_{\mathrm{ad}}$ unit cells were found in STM measurements. For example, depending on the electrode potential and the surface coverage of $\mathrm{CO}_{\mathrm{ad}}$, Oda et al. observed either complex $\mathrm{CO}$ structures or the $(\sqrt{3} \times \sqrt{3}) \mathrm{R}^{\circ} 0^{\circ}$ structure $^{20}$, which was previously observed in ex-situ measurements ${ }^{21 ; 22}$. On the other hand, above $0 \mathrm{~V}$ (vs SCE) in solution containing CO Villegas and Weaver found a $(\sqrt{19} \times \sqrt{19}) \mathrm{R} 23.4^{\circ}$ structure $^{6}$. At potentials below 0.2 (vs. SCE), after the removal of solution-phase $\mathrm{CO}$, another $\mathrm{CO}$ adlayer structure with the $(\sqrt{7} \times \sqrt{7}) \mathrm{R} 19.1^{\circ}$ symmetry was also reported from the latter authors ${ }^{6}$. Although a careful search was made to find diffraction peaks due to domain structures based on either the $\sqrt{3}$ symmetry or the $(\sqrt{19} \times \sqrt{19}) R 23.4^{\circ}$ and $(\sqrt{7} \times \sqrt{7})$ phases, such superlattice $\mathrm{CO}_{\text {ad }}$ peaks were not found in SXS measurements at any partial pressure of $\mathrm{CO}$ and at any surface coverage by CO. It was concluded, therefore, that the $\mathrm{p}(2 \times 2)-3 \mathrm{CO}$ structure is the only structure present with long-range order ${ }^{8}$. A rocking scan through the $(1 / 2,1 / 2,0.2)$ position is shown in Figure $3 b$ together with the fit of a Lorentzian lineshape (solid line) to the data. From the width of this peak and from the result of similar fits to other $\mathrm{p}(2 \times 2)$ reflections a coherent domain size in the range of $80-120 \AA$ for the $\mathrm{CO}$ adlayer was deduced ${ }^{5 ; 8}$. The derived structural model is shown schematically in Figure 3, which consists of three CO molecules per $\mathrm{p}(2 \times 2)$ unit cell. It is important to note, however, that besides the symmetry of the ordered CO structure, SXS measurements were unable to provide 
information about the real sites occupancy in the unit cell. Closely following ref. ${ }^{6}$, these information are obtained from FTIR measurements.

Fig.2c shows a set of the absorbance spectra referred to the single beam spectrum collected at $1.0 \mathrm{~V}$. As previously described by different authors ${ }^{23-26}$ characteristic C-O stretching bands near 2070 and near $1780 \mathrm{~cm}^{-1}$, corresponding to a-top and three-fold hollow $\mathrm{CO}$ respectively, predominates in the spectra obtained at potentials below $0.50 \mathrm{~V}$. At higher potentials, the three-fold hollow band is replaced by a new $\mathrm{C}-\mathrm{O}$ stretching band at ca. $1840 \mathrm{~cm}^{-1}$ that can be related to the presence of bridge-bonded CO. Plots for the integrated intensity of the observed $\mathrm{C}-\mathrm{O}$ stretching bands as a function of the electrode potential are summarized in Figure 2b. Comparison of the potential dependent intensity changes for the three-fold and bridge CO bands with the SXS ${ }^{9}$ data suggests that the three-fold hollow band is related to the $(2 \times 2)-3 \mathrm{CO}$ structure whereas the loss of this ordered structure is reflected by the appearance of the bridge-bonded CO band. Based on the analysis of the C-O vibrational spectra obtained for a series of stepped surfaces with (111) terraces, the $\mathrm{p}(2 \times 2)-3 \mathrm{CO}$ structure in $\mathrm{CO}$-saturated $\mathrm{HClO}_{4}$ solution is also sensitive to the two-dimensional long-range order of the $\operatorname{Pt}(111)^{25}$ surface.

At this point it should be recalled that changes of the band intensities for adsorbed $\mathrm{CO}$ with potential as plotted in Figure $2 \mathrm{~b}$ must be interpreted with caution. Qualitatively, and in agreement with refs. ${ }^{6 ; 9}$ we can conclude that the order-disorder transition in the $\mathrm{CO}$ adlayer is mirrored by the disappearance of $\mathrm{CO}_{\mathrm{ad}}$ from the three-fold hollow sites, and the relaxation of the remaining $\mathrm{CO}_{\mathrm{ad}}$ into a combination of bridge sites and a-top sites. However, whereas the intensity of the a-top band at saturation coverage is higher than that of multi-coordinate $\mathrm{CO}$, examination of the real-space model of the $\mathrm{p}(2 \times 2)-3 \mathrm{CO}$ structure in Figure 3, shows that about $1 / 3$ of the $\mathrm{CO}_{\mathrm{ad}}$ occupy a-top sites, and $2 / 3$ are in three-fold hollow sites. The stronger a-top signal observed with IR spectroscopy can be explained by "intensity stealing" by which the higher-frequency a-top mode gains intensity over the lower frequency hollow-site mode ${ }^{27}$. Quantitation of the intensity 
changes to fractional coverages can only be done with modeling of the dipole coupling, and even then would entail assumptions about the $\mathrm{CO}_{\mathrm{ad}}-\mathrm{CO}_{\mathrm{ad}}$ coordination as the coverage changes ${ }^{27}$.

Another point that can be clarified from the in-situ infrared experiments performed with the CO-covered $\mathrm{Pt}(111)$ electrode is that of the relation between the loss of the $(2 \times 2)$ structure and the onset of CO oxidation. Recall that comparison of the SXS and voltammetric data suggested that the disordering transition is governed by electrooxidation of a relatively small amount of $\mathrm{CO}_{\mathrm{ad}}, c a .15 \%{ }^{5}$. This can be confirmed from Fig.2a, which provides a quantitative measure of $\mathrm{CO}_{2}$ formation from the asymmetric O-C-O stretch at $2343 \mathrm{~cm}^{-1}$. To obtain this plot, the same set of single potential spectra used to obtain the difference spectra in Fig.2c was now referred to the reference spectrum collected at $0.10 \mathrm{~V}$. Compared with Figure $2 \mathrm{~b}, \mathrm{CO}_{2}$ production occurs simultaneously with the binding site occupancy change, indicating that structural transformation in the $\mathrm{CO}_{\mathrm{ad}}$ layer is triggered by oxidative removal of $\mathrm{CO}_{\mathrm{ad}}$, as in equation 1. Interestingly, the $\mathrm{CO}_{2}$ plot shows two (positive) slopes: the low- $\mathrm{CO}_{2}$ slope between $0.5 \mathrm{~V}$ and $0.7 \mathrm{~V}$ corresponds to the pre-ignition region were disappearance of the three-fold hollow sites is observed in Figure 2b, and the high $\mathrm{CO}_{2}$-slope above $0.7 \mathrm{~V}$ that is related to the oxidation of a-top and bridge $\mathrm{CO}_{\mathrm{ad}}$ in the ignition potential region. Point of inflection in the $\mathrm{CO}_{2}$ slope may correspond to the "ignition potential", which is defined in section 3.1. Therefore, linking macroscopic and macroscopic characterization of the $\operatorname{Pt}(111)-\mathrm{CO}$ system, the macroscopic terminology of $\mathrm{CO}_{\mathrm{ad}, \mathrm{w}}$ may correspond microscopically to a saturated $\mathrm{CO}_{\mathrm{ad}}$ layer consisting of three $\mathrm{CO}$ molecules per $\mathrm{p}(2 \times 2)$ unit cell located in a-top and three-fold hollow sites. Figure 2 shows that oxidation of the $\mathrm{CO}_{\mathrm{ad}}$ in the three-fold hollow sites and relaxation of the remaining $\mathrm{CO}_{\mathrm{ad}}$ into bridge sites and a-top sites disrupts the long-range ordering in the remaining adlayer, as the Bragg peak intensity for the $\mathrm{p}(2 \times 2)-3 \mathrm{CO}$ structure decreases rapidly in this potential region (Figure 2c). The characterized microscopically as "relaxed" $\mathrm{CO}_{\mathrm{ad}}$ adlayer with 
substantial alternation in binding site geometry from predominantly three-fold hollow to bridge sites can be linked macroscopically to the strongly adsorbed state of $\mathrm{CO}_{\mathrm{ad}}$ that is oxidized in the ignition potential region.

Figures 4 and 5 show that the anions in the supporting electrolyte do affect the stability of the $\mathrm{p}(2 \times 2)-3 \mathrm{CO}$ structure. Combined SXS/FTIR data for the Pt(111)-CO $\mathrm{CO}_{\mathrm{ad}}$ system in alkaline solution (Figure 4) and in perchloric acid solution containing $\mathrm{Br}^{-}$ (Figure 5) are representative examples. Clearly, in alkaline solution the oxidation of CO (production of $\mathrm{CO}_{3}{ }^{2-}$ in Figure $4 \mathrm{a}$ ) begins as low as at $0.3 \mathrm{~V}$, concurrent with the loss of $\mathrm{CO}_{\mathrm{ad}}$ at three-fold hollow sites (band at $1733 \mathrm{~cm}^{-1}$ in the spectra shown in Fig.4c) and the development of $\mathrm{CO}_{\mathrm{ad}}$ at bridge sites (band at ca. $1804 \mathrm{~cm}^{-1}$ ), Figure $4 \mathrm{~b}$. Note that the observation of the C-O stretching bands at lower wavenumbers than in Fig.2c is related to the lower surface potential in alkaline solutions $24{ }^{24}$. The oxidation of $\mathrm{CO}$ at very low potentials in alkaline solution reduces the potential range of the stability of the $\mathrm{p}(2 \times 2)-3 \mathrm{CO}$ structure, $0.05-0.35 \mathrm{~V}$ in $\mathrm{KOH}$ versus $0.05-0.6 \mathrm{~V}$ in $\mathrm{HClO}_{4}$. We argued in reference ${ }^{10}$ and in the previous section on kinetics of $\mathrm{CO}$ oxidation that $\mathrm{CO}_{\mathrm{ad}}$ is oxidatively removed by $\mathrm{OH}_{\mathrm{ad}}$ adsorbed at the defect/step sites on the $\operatorname{Pt}(111)$ surface. The adsorption of $\mathrm{OH}$ onto these sites is facile in alkaline solution, and consequently the production of $\mathrm{CO}_{3}{ }^{2-}$ is observed even in the $\mathrm{H}_{\text {upd }}$ potential region. In solution containing $\mathrm{Br}^{-}$, however, these defect/step sites are blocked with $\mathrm{Br}_{\mathrm{ad}}$, thus the potential stability of the $\mathrm{p}(2 \times 2)-3 \mathrm{CO}$ structure and $\mathrm{CO}_{2}$ prodution is extended to higher potential than even in perchloric acid solution, see Figure 5. This figure also shows that the complete stripping of the $\mathrm{CO}$ adlayer remaining on the $\mathrm{Pt}(111)$ surface once the (2x2) structure disappears is shifted towards more positive potentials. In this way, the bridge bonded $\mathrm{CO}$ band is observed in a relatively broad potential region between 0.70 and $0.90 \mathrm{~V}$. As in perchloric acid, $\mathrm{CO}_{2}$ plot in Figure 5a shows two positive slopes that can be related to the oxidation of $\mathrm{CO}_{\mathrm{ad}}$ the pre-ignition and ignition potential regions. Note that in alkaline solution the 
transition from the pre-ignition to the ignition potential region is less clear from the plot of $\mathrm{CO}_{3}{ }^{2-}$ intensity which is shown in Figure $4 \mathrm{a}$.

Finally, it is also worth mentioning that besides tuning the fine balance between a-top and multifold coordinated $\mathrm{CO}_{\mathrm{ad}}$, the domain size of the $\mathrm{CO}_{\mathrm{ad}}$ structure is significantly affected by the nature of anions. Figure 3 shows rocking scans through the $(1 / 2,1 / 2,0.2)$ position measured at $0.05 \mathrm{~V}$ in three different electrolytes. The solid lines are fitted Lorentzian lineshapes to the data, and from these data and from other measured reflections ( a total of nine symmetry independent reflections ${ }^{8}$ ) a domain size in the range 30-350 $\AA$ was calculated. The domain size of the $\mathrm{p}(2 \times 2)-3 \mathrm{CO}$ structure increases from $\mathrm{KOH}(c a .30 \AA)$, to $\mathrm{HClO}_{4}(c a .140 \AA)$ to $\mathrm{HClO}_{4}+\mathrm{Br}^{-}($ca $350 \AA)$, i.e., the less active the surface is towards $\mathrm{CO}_{\mathrm{ad}}$ oxidation, the larger the ordered domains of the $\mathrm{p}(2 \times 2)-3 \mathrm{CO}$ structure was observed in SXS measurements. A self-consistent explanation for this result is that both the stability and domain size of the ordered $\mathrm{CO}_{\mathrm{ad}}$ adlayer is determined by the potential dependent competition between $\mathrm{OH}_{\mathrm{ad}}$ and spectator anions for the defect/step sites on the $\operatorname{Pt}(111)$ surface ${ }^{10}$.

\section{CONCLUSIONS}

In-situ studies of $\mathrm{CO}$ adsorption by surface $\mathrm{x}$-ray scattering (SXS) and Fourier transform infrared (FTIR) spectroscopy have been used to create the link between the macroscopic kinetic rate of $\mathrm{CO}$ oxidation and the microscopic level of understanding the structure/site occupancy of $\mathrm{CO}$ on $\mathrm{Pt}(111)$. A remarkable difference in activity was observed between alkaline and acid solutions. In alkaline solution, the oxidation of $\mathrm{CO}$ proceeds at low overpotential $(<0.2 \mathrm{~V})$ between the adsorbed $\mathrm{CO}$ and $\mathrm{OH}$, the latter forming selectively in hydrogen underpotential region at defect sites. In acid solution these sites are blocked by specific adsorption of anions, and consequently in solution containing $\mathrm{Br}^{-}$the ignition potential is shifted by $0.6 \mathrm{~V}$ positively. The anions of supporting electrolyte have also dramatic effects on the potential range of stability and the 
domain size of the $\mathrm{p}(2 \mathrm{x} 2)-3 \mathrm{CO}$ structure, which is formed at $0.05 \mathrm{~V}$. The stability/domain size of this structure increases from $\mathrm{KOH}$ ( $c$ a. $30 \AA$ between 0.05 $<\mathrm{E}<0.3 \mathrm{~V})$, to $\mathrm{HClO}_{4}(c a .140 \AA$ between $0.05<\mathrm{E}<0.6 \mathrm{~V})$ to $\mathrm{HClO}_{4}+\mathrm{Br}^{-}($ca $350 \AA$ between $0.05<\mathrm{E}<0.8 \mathrm{~V}$ ), the larger the ordered domains are, the less active the surface is towards $\mathrm{CO}$ oxidation.

\section{ACKNOWLEDGMENT}

This research was supported by the Office of Science, Basic Energy Sciences, Material Sciences Division of the U.S. Department of Energy under Contract No. DEAC03-76SF00098. Research carried out in part at SSRL which is funded by the Division of Chemical Sciences(DSC), US DOE. CAL acknowledges the support of an EPSRC Advanced Research Fellowship. 


\section{REFERENCES}

1 Ertl, G.; Neumann, N.; Streit, K.M. Surf.Sci. 1977, 64, 393-410.

2 Thiel, P.A.; Behm, R.J.; Norton, P.R.; Ertl, G. J.Chem.Phys. 1983, 78, 7448-7458.

3 Lee, W.T.; Ford, L.; Blowers, P.; Nigg, H.L.; Masel, R.I. Surf.Sci. 1998, 416, 141151.

4 Markovic, N.M.; Lucas, C.; Grgur, B.N.; Ross, P.N. J.Phys.Chem. 1999, 103, 96169623.

5 Markovic, N.M.; Grgur, B.N.; Lucas, C.A.; Ross, P.N. J.Phys.Chem.B 1999, 103, 487-495.

6 Villegas, I.; Weaver, M.J. J.Chem.Phys. 1994, 101, 1648

7 Villegas, I.; Gao, X.; Weaver, M.J. Electrochim.Acta 1995, 40, 1267-1275.

8 Lucas, C.A.; Markovic, N.M.; Ross, P.N. Surf.Sci. 1999, 425, L381-L386

9 Markovic, N.M.; Ross, P.N. Electrochim.Acta 2000,

10 Markovic, N.M.; Schmidt, T.J.; Grgur, B.N.; Gasteiger, H.A.; Ross Jr., P.N.; Behm, R.J. J.Phys.Chem.B 1999, 103, 8568-8577.

11 Markovic, N.M.; Gasteiger, H.A.; Ross, P.N. J.Phys.Chem. 1995, 99 , 3411-3415.

12 Clavilier, J.; Armand, D.; Sun, S.G.; Petit, M. J.Electroanal.Chem. 1986, 205, 267277.

13 Wieckowski, A.; Rubel, M.; Gutiérrez, C. J.Electroanal.Chem. 1995, 382, 97-101. 
14 Kita, H.; Naohara, H.; Nakato, T.; Taguchi, S.; Aramata, A. J.Electroanal.Chem. 1995, 386, 197-206.

15 Bergelin, M.; Feliu, J.M.; Wasberg, M. Electrochim.Acta 1998, 44, 1069-1075.

16 Bergelin, M.; Herrero, E.; Feliu, J.M.; Wasberg, M. J.Electroanal.Chem. 1999, 467, 74-84.

17 Schmidt, T.J.; Markovic, N.M.; Ross Jr., P.N. submitted in J.Phys.Chem 2001,

18 Lebedeva, N.P.; Koper, M.; Herrero, E.; Feliu, J.M.; van Santen, R.A. J.Electroanal.Chem. 2000, 487, 37-44.

19 Markovic, N.M.; Ross Jr., P.N. Cat.Tech. 2000,

20 Oda, I.; Inukai, J.; Ito, M. Chem.Phys.Lett. 1993, 203, 99-103.

21 Zurawski, D.; Wasberg, M.; Wieckowski, A. J.Phys.Chem. 1990, 94, 2076-2082.

22 Lin, W.-F.; Iwasita, T.; Vielstich, W. J.Phys.Chem.B 1999, 103, 3250-3257.

23 Kitamura, T.; Takahashi, M.; Ito, M. Surf.Sci. 1989, 358, 337

24 Chang, S.C.; Weaver, M.J. Surf.Sci. 1990, 238, 42

25 Rodes, A.; Gomez, R.; Feliu, J.M.; Weaver, M.J. Langmuir 2001, 16, 811-816.

26 Akemann, W.; Friedrich, K.A.; Stimming, U. J.Phys.Chem. 2000, 113, 6864-6874.

27 Severson, M.W.; Stuhlmann, C.; Villegas, I.; Weaver, M.J. J.Chem.Phys. 1995, 103, 9832-9843. 


\section{FIGURE CAPTIONS}

Figure 1. Potentiodynamic $\mathrm{CO}_{\mathrm{b}}$ oxidation current densities on $\operatorname{Pt}(111)$ in $0.1 \mathrm{M} \mathrm{HClO}_{4}+10^{-2} \mathrm{M} \mathrm{Br}^{-} ; 0.1 \mathrm{M} \mathrm{HClO}_{4}$; and $0.1 \mathrm{M} \mathrm{KOH}$. Sweep rate $20 \mathrm{mV} / \mathrm{s}$. Rotation rate $900 \mathrm{rpm}$.

Figure 2. . (a) Potential-dependent stability of the $\mathrm{p}(2 \times 2)-3 \mathrm{CO}_{\mathrm{ad}}$ structure on $\operatorname{Pt}(111)$ in $0.1 \mathrm{M} \mathrm{HClO}_{4}$ in $\mathrm{CO}$-saturated solution, and $\mathrm{CO}_{2}$ production as a function of electrode potential (data extracted from FTIR measurement) during the oxidation of $\mathrm{CO}_{\mathrm{ad}}$. Integrated intensities for $\mathrm{CO}_{a d}$-atop, $\mathrm{CO}_{a d}$-multi and $\mathrm{CO}_{\text {add }}$-bridge on $\mathrm{Pt}(111)$ as a function of electrode potential in $\mathrm{CO}$-saturated $0.1 \mathrm{M} \mathrm{HClO}_{4}$ solution. (c) FTIR spectra obtained during progressive oxidation of $\mathrm{CO}_{\mathrm{ad}}$ on $\mathrm{Pt}(111)$ in $0.1 \mathrm{M} \mathrm{HClO}_{4}$ from the initial potential, $c a$. $E=0.05 \mathrm{~V}$. Each spectrum, displayed as relative reflectance $(\Delta \mathrm{R} / \mathrm{R})$, was acquired from 100 interferometer scans at the range potential indicated, rationed to the corresponding spectrum obtained at the final potential, $c a$. E=0.9 V.

Figure 3. Rocking scans through the $(1 / 2,1 / 2,0.2)$ reciprocal lattice position, where scattering from the $\mathrm{p}(2 \times 2)-3 \mathrm{CO}$ structure is observed, for (a) $0.1 \mathrm{M} \mathrm{HClO}_{4}+10^{-2} \mathrm{M} \mathrm{Br}^{-}$, (b) $0.1 \mathrm{M} \mathrm{HClO}_{4}$ and (c) $0.1 \mathrm{M} \mathrm{KOH}$. The solid lines are fits of a Lorentzian lineshape to the data which give a coherent domain size for the p(2x2) structure of $350 \AA$ $30 \AA$ in (a), (b) and (c) respectively. Also shown is a schematic picture of the p(2x2)3CO structure. The symmetry of the unit cell ad the site f occupancy are deermined from SXS and FTIR measurements, respectively. 
Figure 4. (a) Potential-dependent stability of the $\mathrm{p}(2 \mathrm{x} 2)-3 \mathrm{CO}_{\mathrm{ad}}$ structure on $\mathrm{Pt}(111)$ in $0.1 \mathrm{M} \mathrm{NaOH}$ in $\mathrm{CO}$-saturated solution, and $\mathrm{CO}_{3}{ }^{2-}$ production as a function of electrode potential (data extracted from FTIR measurement) during the oxidation of $\mathrm{CO}_{\mathrm{ad}}$. (b) Integrated intensities for $\mathrm{CO}_{\mathrm{ad}}$-atop, $\mathrm{CO}_{\mathrm{ad}}$-multi and $\mathrm{CO}_{\mathrm{ad}}$-bridge on $\mathrm{Pt}(111)$ as a function of electrode potential in $\mathrm{CO}$-saturated $0.1 \mathrm{M} \mathrm{NaOH}$ solution. (c) FTIR spectra obtained during progressive oxidation of $\mathrm{CO}_{\mathrm{ad}}$ on $\mathrm{Pt}(111)$ in $0.1 \mathrm{M} \mathrm{NaOH}$ from the initial potential, $c a$. $E=0.05 \mathrm{~V}$. Each spectrum, displayed as relative reflectance $(\Delta R / R)$, was acquired from 100 interferometer scans at the range potential indicated, rationed to the corresponding spectrum obtained at the final potential, $c a . \mathrm{E}=0.9 \mathrm{~V}$.

Figure 5(a) Potential-dependent stability of the $\mathrm{p}(2 \mathrm{x} 2)-3 \mathrm{CO}_{\mathrm{ad}}$ structure on $\mathrm{Pt}(111)$ in $0.1 \mathrm{M} \mathrm{HClO}_{4}+10^{-2} \mathrm{M} \mathrm{Br}^{-}$in $\mathrm{CO}$-saturated solution, and $\mathrm{CO}_{2}$ production as a function of electrode potential (data extracted from FTIR measurement) during the oxidation of $\mathrm{CO}_{\mathrm{ad}}$. (b) Integrated intensities for $\mathrm{CO}_{\mathrm{ad}}$-atop, $\mathrm{CO}_{\mathrm{ad}}$-multi and $\mathrm{CO}_{\mathrm{ad}}$-bridge on $\mathrm{Pt}(111)$ as a function of electrode potential in CO-saturated solution. (c) FTIR spectra obtained during progressive oxidation of $\mathrm{CO}_{\mathrm{ad}}$ on $\mathrm{Pt}(111)$ in $0.1 \mathrm{M} \mathrm{HClO}_{4}+! 0^{-2} \mathrm{M} \mathrm{Br}^{-}$from the initial potential, $c a$. $E=0.05 \mathrm{~V}$. Each spectrum, displayed as relative reflectance $(\Delta R / R)$, was acquired from 100 interferometer scans at the range potential indicated, rationed to the corresponding spectrum obtained at the final potential, $c a$. E= $=0.9 \mathrm{~V}$. 